\title{
The Econometrics of Monetary Policy: an Overview
}

\author{
Carlo A. Favero \\ IGIER-Bocconi University, CEPR and AMeN
}

January 15, 2008

\begin{abstract}
This chapter concentrates on the Econometrics of Monetary Policy. We describe the evolution of models estimated to evaluate the macroeconomic impact of monetary policy. We argue that the main challenge for the econometrics of monetary policy is the combination of theoretical models and information from the data to construct empirical models. The failure of the large econometrics models at the beginning of the 1970s might be explained by their incapability of taking proper account of both these aspects. The great critiques by Lucas and Sims have generated an alternative approach which, at least initially, has been almost entirely dominated by theory. The LSE approach has instead concentrated on the properties of the statistical models and on the best way of incorporating information from the data into the empirical models, paying little attention to the economic foundation of the adopted specification. The realization that the solution of a DSGE model can be approximated by a restricted VAR, which is also a statistical model, has generated a potential link between the two approaches. The open question is which type of VARs are most appropriate for the econometric analysis of monetary policy.

JEL Classification: C10, C52, E50

Keywords:Econometrics, Monetary Policy, identification, DSGE, VAR, FAVAR
\end{abstract}

\section{The Econometrics of monetary policy. What have we learnt ?}

Econometric evaluation of monetary policy started with large simultaneous equation models, in the tradition of the Cowles Commission. This first generation of models was largely driven by the IS/LM framework, in which the supply side was left virtually unmodelled and relative price movements were not considered (see Fukac and Pagan (2006)). Large-scale models were obtained by specifying equations that described the determinants of variables in 
the national accounting identity for GDP, e.g. investment, consumption. This approach aimed at the quantitative evaluation of the effects of modification in the variables controlled by the monetary policy-maker (the instruments of monetary policy) on the macroeconomic variables which represent the final goals of the policy-maker. The analysis was performed in three stages: specification and identification of the theoretical model, estimation of the relevant parameters and assessment of the dynamic properties of the model, with particular emphasis on the long-run properties, and simulation of the effects of monetary policies.

The crucial feature of the identification-specification stage was that the specified empirical model was usually loosely related to theoretical models and that identification was achieved by imposing numerous a priori restrictions attributing exogeneity status to a number of variables. As a consequence, identification was usually achieved within Cowles Commission models with a large number of over-identifying restrictions.

Interestingly, the traditional modelling was aware of the presence of some misspecification in the estimated equations. This resulted in a departure from the conditions which warrant that OLS estimators are best linear unbiased estimators (BLUE). The solution proposed was not re-specification but, instead, a modification of the estimation techniques. This is well reflected in the structure of the traditional textbooks: see, for example, Goldberger (1991), where the OLS estimator is introduced first and then different estimators are considered as solutions to different pathologies in the model residuals. Pathologies are identified as departures from the assumptions which guarantee that OLS estimators are BLUE.

Stagflation condemned the first generation models in the late 1970s, as they

"...did not represent the data, ... did not represent the theory... [and] were ineffective for practical purposes of forecasting and policy evaluation..." (Pesaran and Smith, 1995).

Different explanations of the failure of these models were proposed. We classify them into diagnoses related to the solution of the structural identification problem and diagnoses related to the (lack of ) solution of the statistical identification problem.

The distinction between structural and statistical identification has been introduced by Spanos (1990). Structural models can be viewed statistically as a reparameterization, possibly (in the case of over-identified models) with restrictions, of the reduced form. Structural identification refers to the uniqueness of the structural parameters, as defined by the reparameterization and restriction mapping from the statistical parameters in the reduced form, while statistical identification refers to the choice of a well-defined statistical model as the reduced form.

The Lucas (1976) and Sims(1980) critiques are the diagnoses related to the solution of the identification problem. Lucas questions the superexogeneity status of the policy variables. and criticizes the identification scheme proposed by 
the Cowles Commission by pointing out that these models do not take expectations into account explicitly. Therefore, the identified parameters within the Cowles Commission approach are a mixture of 'deep parameters', describing preference and technology in the economy, and expectational parameters which, by their nature, are not stable across different policy regimes. The main consequence of such instability is that traditional structural macro-models are useless for the purpose of policy simulation.

Sims reinforced Lucas' point by labelling the Cowles Commission restrictions as "incredible"; in fact, no variable can be deemed as exogenous in a world of forward-looking agents whose behaviour depends on the solution of an intertemporal optimization model. Optimality of monetary policy requires its endogeneity. Note also that, by invalidly imposing exogeneity of monetary policy, the model might induce a spuriously significant effectiveness of policy in the determination of macroeconomic variables. Endogeneity of policy does generate correlations between macroeconomic and policy variables, which, by invalidly assuming policy as exogenous, can be interpreted as a causal relation running from policy to the macroeconomic variables.

The diagnosis related to the specification of the statistical model explains the ineffectiveness of the Cowles Commission models for the practical purposes of forecasting and policy as due to their incapability of representing the data. The root of the failure of the traditional approach lies in the inadequate attention paid to the statistical model implicit in the estimated structure. The diagnosis related to the specification of the statistical model gave rise to the LSE approach to macroeconometric modelling ${ }^{1}$ and to the "structural cointegrating VAR" approach. The LSE approach has greatly emphasized the importance of a correct dynamic specification of the reduced form model and has placed very little emphasis on the explicit modelling of the economy based on intertemporal optimization. Recently the link between theory and dynamic specification has been re-established by a research approach based on the belief that economic theory is most informative about the long-run relationships between the relevant variables and proposed by Hashem Pesaran and a number of co-authors (see, for example, Pesaran and Shin (2002), Garratt et al.(2006)) in the so-called "structural cointegrating VAR approach". This approach is based on testing theory based over-identifying restrictions on the long-run relations to provide a statistically coherent framework for the analysis of the short-run.

The Lucas and Sims critiques have instead generated a totally new approach to econometric policy evaluation. These great critiques made clear that questions like 'How should a central bank respond to shocks in macroeconomic variables?' are to be answered within the framework of quantitative monetary general equilibrium models of the business cycle. So the answer should rely on a theoretical model rather than on an empirical ad hoc macroeconometric model. Initially this approach led to the construction of Real Business Cycle (RBC) models where monetary policy played no role in explaining macroeco-

${ }^{1}$ The LSE approach was initiated by Denis Sargan but owes its diffusion to a number of Sargan's students and is extremely well described in the book by David Hendry (1995). 
nomic fluctuations. Moreover, these models depended on a limited numbers of structural parameters that were not estimated but rather calibrated. This period has been labelled by John Taylor (2005) as the "dark age" of the econometrics of monetary policy. This "dark age" came to end as a consequence of developments in macroeconomic theory and empirical modelling. On the theory side, the realization of the importance of price stickiness and of slow adjustment to the forward looking rational expectations equilibria led to the "renaissance" of the role of monetary policy in understanding macroeconomic fluctuations. At the same time a new role was attributed to empirical analysis of providing evidence on the stylized facts to include in the theoretical model adopted for policy analysis and deciding between competing general equilibrium monetary models. This new role emerged with the realization that the solution of a Dynamic Stochastic General Equilibrium (DSGE) model can be well approximated by a Vector AutoRegressive model (VAR), and VARs have become the natural tool for model evaluation.

The use of VARs led to the establishment of a number of facts and features to be included in models for monetary policy evaluation, well described by Christiano, Eichenbaum and Evans (2005) and Sims (2007).

(i) Since VAR models are not estimated to yield advice on the best policy but rather to provide empirical evidence on the response of macroeconomic variables to policy impulses in order to discriminate between alternative theoretical models of the economy, it then becomes crucial to identify policy actions using restrictions independent from the theoretical models of the transmission mechanism under empirical investigation, taking into account the potential endogeneity of policy instruments.

(ii) Most of the monetary actions are systematic responses to the state of the economy, so there is very little in the way of random fluctuations in policy to produce business cycles

(iii) Money supply is close to a random walk and monetary aggregate shocks do not look like monetary policy shocks in their effect. The foundation of the way people think about monetary policy is based on interest rate adjustments.

The main results of the VAR based evaluation model is that, in order to match fluctuations in the data, any model must feature some attrition that causes temporary but rather persistent deviations from the long-run equilibrium defined by a frictionless neoclassical economy.

Adding frictions implies increasing the number of parameters, especially along the dimension of parameters little related to theory. As a consequence calibration became impractical for attributing numerical values to the DSGE parameters and estimation came back into fashion. However, estimating DSGE models by classical maximum likelihood methods proved to be very hard as the convergence of the estimates to values that ensure a unique stable solution turned out to be practically impossible to achieve when implementing unconstrained maximum likelihood estimation. Note that three types of solution are possible for a DSGE model, depending on its parameterization: no stable rational expectations solution exists, the stable solution is unique (determinacy), or there are multiple stable solutions (indeterminacy). Determinacy is a prerequi- 
site in order to use a model to simulate the effects of economic policy ${ }^{2}$.

The practical impossibility of applying the classical maximum likelihood principle to estimate DSGE models paved the way for Bayesian methods. These methods have been used both for parameter estimation (see, for example, Smets and Wouters (2003)) and model evaluation (Del Negro et al. (2004)). As clearly pointed out by Sims (2007) this practice leads to a new interaction between theory and empirical analysis where the theoretical DSGE model should not be considered as a model for the data but as a generator of prior distribution for the empirical model.

\section{The econometrics of monetary policy in large econometric models.}

Consider a model designed to evaluate the effect of monetary policy. A first generation structural model can be represented as follows:

$$
\begin{aligned}
\mathbf{A}\left(\begin{array}{c}
\mathbf{Y}_{t} \\
\mathbf{M}_{t}
\end{array}\right) & =\mathbf{C}_{1}(L)\left(\begin{array}{c}
\mathbf{Y}_{t-1} \\
\mathbf{M}_{t-1}
\end{array}\right)+\mathbf{B}\left(\begin{array}{c}
\boldsymbol{\nu}_{t}^{Y} \\
\boldsymbol{\nu}_{t}^{M}
\end{array}\right), \\
\left(\begin{array}{c|c}
\boldsymbol{\nu}_{t}^{Y} \\
\boldsymbol{\nu}_{t}^{M}
\end{array} \mid I_{t-1}\right) & \sim(\mathbf{0}, \mathbf{I}) .
\end{aligned}
$$

The vector of $n$ variables of interest is partitioned into two subsets: $\mathbf{Y}$, which represents the vector of macroeconomic variables of interest and $\mathbf{M}$, the vector of monetary policy variables determined by the interaction between the policy maker and the economy.

The probabilistic structure for the variables of interest is determined by the implied reduced form. This statistical model has the following representation:

$$
\begin{aligned}
\left(\begin{array}{c}
\mathbf{Y}_{t} \\
\mathbf{M}_{t}
\end{array}\right) & =D_{1}(L)\left(\begin{array}{c}
\mathbf{Y}_{t-1} \\
\mathbf{M}_{t-1}
\end{array}\right)+\mathbf{u}_{t}, \\
\mathbf{u}_{t} & =\left(\begin{array}{c}
\mathbf{u}_{t}^{Y} \\
\mathbf{u}_{t}^{M}
\end{array}\right), \\
u_{t} & \mid I_{t-1} \sim \text { n.i.d. }\left(\mathbf{0}, \sum\right), \\
\left(\begin{array}{c}
\mathbf{Y}_{t} \\
\mathbf{M}_{t} \mid I_{t-1}
\end{array}\right) & \sim\left(D_{1}(L)\left(\begin{array}{c}
\mathbf{Y}_{t-1} \\
\mathbf{M}_{t-1}
\end{array}\right), \sum\right) .
\end{aligned}
$$

\footnotetext{
${ }^{2}$ Importantly, the analysis of determinacy of the equilibria led to the discovery that a central bank can need fiscal backing; in fact, there is a class of equilibria for the economy that are invisible if one focuses entirely on money demand. These are equilibria in which the monetary authority is completely passive : it picks a nominal interest rate and agrees to accommodate any amount of debt issue by monetizing it. In conventional models this leads to an indeterminate price level, but in a model in which the fiscal authority is committed to a fixed level of primary surpluses there is a unique price level. So inflation cannot be controlled by only controlling the stock of money (see Leeper (1991), Sims (2005)).
} 
This system specifies the statistical distribution for the vector of variables of interest conditional upon the information set available at time $t-1{ }^{3}$ In relating the structure of interest to the statistical model a crucial identification problem has to be solved, since there is more than one structure of economic interest which can give rise to the same statistical model for our vector of variables.

Any given structure (1) will give rise to the observed reduced form (2) when the following restrictions are satisfied:

$$
\mathbf{A}^{-1} \mathbf{C}_{1}(L)=D_{1}(L), \quad \mathbf{A}\left(\begin{array}{c}
\mathbf{u}_{t}^{Y} \\
\mathbf{u}_{t}^{M}
\end{array}\right)=\mathbf{B}\left(\begin{array}{c}
\boldsymbol{\nu}_{t}^{Y} \\
\boldsymbol{\nu}_{t}^{M}
\end{array}\right) .
$$

There exists a whole class of structures which produce the same statistical model (2) under the same class of restrictions:

$$
F \mathbf{A}\left(\begin{array}{c}
\mathbf{Y}_{t} \\
\mathbf{M}_{t}
\end{array}\right)=F \mathbf{C}_{1}(L)\left(\begin{array}{c}
\mathbf{Y}_{t-1} \\
\mathbf{M}_{t-1}
\end{array}\right)+F \mathbf{B}\left(\begin{array}{c}
\boldsymbol{\nu}_{t}^{Y} \\
\boldsymbol{\nu}_{t}^{M}
\end{array}\right)
$$

where $F$ is an admissible matrix, i.e. it is conformable by product with $\mathbf{A}$, $\mathbf{C}_{1}(L)$, and $\mathbf{B}$, and $F \mathbf{A}, F \mathbf{C}_{1}(L), F \mathbf{B}$ feature the same restrictions as $\mathbf{A}, \mathbf{C}_{1}(L)$, B.

The identification problem is solved in the Cowles Commission approach by imposing restrictions on the $\mathbf{A}, \mathbf{C}_{1}(L)$ and $\mathbf{B}$ matrices so that the only admissible $F$ matrix is the identity matrix. This is typically achieved by attributing an exogeneity status to the policy variables. Engle, Hendry and Richard (1983) illustrate that estimation requires weak exogeneity ( $\mathbf{A}$ and $\mathbf{B}$ lower triangular), forecasting requires strong exogeneity $\left(\mathbf{A}, \mathbf{C}_{1}(L)\right.$ and $\mathbf{B}$ lower triangular), while policy simulation requires superexogeneity, i.e. strong exogeneity plus invariance of the parameters of interest to changes in the distribution of the policy variables.

Having identified the model and estimated the parameters of interest, the effect of monetary policy can be simulated. For given values of the parameters and the exogenous variables, values for the endogenous variables are recovered by finding the dynamic solution of the model.

Dynamic simulation is used to evaluate the effect of different policies, defined by specifying different patterns for the exogenous variables. Policy evaluation is implemented by examining how the predicted values of the endogenous variables change after some exogenous variables are modified. This implies simulating the model twice. First, a baseline, control, simulation is run. Such simulations can be run within the sample, in which case observed data are available for the exogenous variables, or outside the available sample, and values are assigned to the exogenous variables. The results of the baseline simulations are then compared with those obtained from an alternative, disturbed, simulation, based on the modification of the relevant exogenous variables. Policy evaluation was

\footnotetext{
${ }^{3}$ The statistical model is a VAR. When variables included in the VAR are non-stationary, the model can be re-parameterised as a VECM. In this case, after the solution of the identification problems of cointegrating vectors, the information set available at $t-1$ contains $n$ lagged endogenous variables and $r$ cointegrating vectors.
} 
usually based on dynamic multipliers, which show the effect over time of the modification in the exogenous variables.

The construction of diagnostics for model evaluation is related to the solution of the identification problem. In fact, in the (very common) case of overidentified models, a test of the validity of the over-identifying restrictions can be constructed by comparing the restricted reduced form implied by the structural model with the reduced form implied by the just-identified model in which each endogenous variable depends on all exogenous variables with unrestricted coefficients. The statistics are derived in Anderson and Rubin (1949) and Basman (1960). The logic of the test attributes a central role to the structural model. The statistical model of reference for the evaluation of the structural model is derived from the structural model itself.

\section{The different diagnoses of the failure of large econometric models.}

The monetary policies based on first generation models failed to prevent stagflation in the late 1970s. There are different explanations of this failure, which focussed either on structural identification or on statistical identification.

\subsection{Diagnoses related to structural identification}

Lucas (1976) questions the superexogeneity status of the policy variables. He attacks the identification scheme proposed by the Cowles Commission by pointing out that these models do not take expectations into account explicitly and, therefore, the identified parameters within the Cowles Commission approach are a mixture of 'deep parameters', describing preferences and technology in the economy, and expectational parameters which, by their nature, are not stable across different policy regimes. The main consequence of such instability is that traditional structural macro-models are useless for the purpose of policy simulation. To illustrate the point, assume the following DGP, in which expected monetary policy matters for the determination of macroeconomic variables in the economy:

$$
\left(\begin{array}{c}
\mathbf{Y}_{t} \\
\mathbf{M}_{t}
\end{array}\right)=\left(\begin{array}{c}
c_{01} \\
c_{02}
\end{array}\right)+\left(\begin{array}{cc}
c_{11} & c_{12} \\
0 & c_{22}
\end{array}\right)\left(\begin{array}{c}
\mathbf{Y}_{t-1} \\
\mathbf{M}_{t-1}
\end{array}\right)+\left(\begin{array}{l}
\gamma \\
0
\end{array}\right)\left(\mathbf{M}_{t+1}^{e}\right)+\left(\begin{array}{c}
\mathbf{u}_{t}^{Y} \\
\mathbf{u}_{t}^{M}
\end{array}\right) .
$$

A Cowles Commission model is estimated without explicitly including expectations and it will have the following specification:

$$
\left(\begin{array}{cc}
1 & a_{12} \\
0 & 1
\end{array}\right)\left(\begin{array}{c}
\mathbf{Y}_{t} \\
\mathbf{M}_{t}
\end{array}\right)=\left(\begin{array}{c}
d_{01} \\
c_{02}
\end{array}\right)+\left(\begin{array}{cc}
d_{11} & d_{12} \\
0 & c_{22}
\end{array}\right)\left(\begin{array}{c}
\mathbf{Y}_{t-1} \\
\mathbf{M}_{t-1}
\end{array}\right)+\left(\begin{array}{c}
\mathbf{u}_{t}^{Y} \\
\mathbf{u}_{t}^{M}
\end{array}\right)
$$

Under the assumed DGP the restrictions $a_{12}=\gamma c_{22}$ and $d_{01}=\gamma c_{02}$ apply and simulation of alternative policy regimes, i.e. alternative values of $c_{02}$ and $c_{22}$, cannot be implemented by keeping the estimated parameters constant. 
Sims (1980) reinforced the Lucas' critique by emphasizing a point originally made by Liu (1960), labelling the traditional restrictions as "incredible". In fact, no variable can be deemed exogenous in a world of forward-looking agents whose behaviour depends on the solution of an intertemporal optimization model. Optimality of policy cannot be consistent with the restrictions that $\mathbf{A}, \mathbf{C}_{1}(L)$, and $\mathbf{B}$ are lower triangular. Note also that, by invalidly imposing such restrictions, the model might induce a spurious statistical effectiveness of policy in the determination of macroeconomic variables. Endogeneity of policy does generate correlations between macroeconomic and policy variables, which, by invalidly assuming policy as exogenous, can be wrongly interpreted as a causal relation running from policy to the macroeconomic variables.

\subsection{Diagnoses related to statistical identification}

The diagnosis related to the specification of the statistical model explains the ineffectiveness of the first generation models for the practical purposes of forecasting and policy as due to their incapability of representing the data. The root of the failure of the traditional approach lies in the lack of attention paid to the statistical model implicit in the estimated structure. Any identified structure is bound to fail if the implied reduced form, i.e. the statistical model, is not an accurate description of the data. The accuracy of the description of the data is to be measured by evaluating the properties of the residuals of the statistical model: "congruent" models should feature residuals that are normally distributed, free of autocorrelation and homoscedastic. Spanos (1990) considers the case of a simple demand and supply model to show how the reduced form is ignored in the traditional approach. The example is based on the market for commercial loans discussed in Maddala (1988). Most of the widely used estimators allow the derivation of numerical values for the structural parameters without even seeing the statistical models represented by the reduced form. Following this tradition, the estimated (by 2SLS) structural model is a static model that relates the demand for loans to the average prime rate, to the Aaa corporate bond rate and to the industrial production index, while the supply of loans depends on the average prime rate, the three-month bill rate and total bank deposits. The quantity of commercial loans and the average prime rate are considered as endogenous while all other variables are taken as, at least, weakly exogenous variables and no equation for them is explicitly estimated. Given that there are two omitted instruments in each equation, one over-identifying restriction is imposed in both the demand and supply equations. The validity of the restrictions is tested via the Anderson-Rubin (1949) tests, and leads to the rejection of the restrictions at the 5 per cent level in both equations, although in the second equation the restrictions cannot be rejected at the 1 per cent level. Estimation of the statistical model, i.e. the reduced form implied by the adopted identifying restrictions, yields a model for which the underlying statistical assumptions of linearity, homoscedasticity, absence of autocorrelation and normality of residuals are all strongly rejected. On the basis of this evidence the adopted statistical model is not considered as appropriate. An alternative 
model is then considered which allows for a richer dynamic structure (two lags) in the reduced form. Such dynamic specification is shown to provide a much better statistical model for the data than the static reduced from. Of course, the adopted structural model implies many more over-identifying restrictions than the initial one. When tested, the validity of these restrictions is overwhelmingly rejected for both the demand and the supply equations. This evidence leads Spanos to conclude that statistical identification should be distinguished from structural identification. Statistical identification refers to the choice of a well-defined statistical model, structural identification refers to the uniqueness of the structural parameters as defined by the reparameterization and restriction mapping from the statistical parameters. Lucas and Sims concentrate on model failure related to structural identification problems, but models can fail independently from structural identification problems as a consequence of lack of statistical identification.

\section{Model specification and model diagnostics when statistical identification matters.}

The diagnosis related to the specification of the statistical model gave rise to the LSE approach to macroeconometric modelling and to the "structural cointegrating VAR" approach.

There are several possible causes for the inadequacy of the statistical models implicit in structural econometric models: omission of relevant variables, or of the relevant dynamics for the included variables, or invalid assumptions of exogeneity. The LSE solution to the specification problem is the theory of reduction. Any econometric model is interpreted as a simplified representation of the unobservable data generating process (DGP). For the representation to be valid or 'congruent', to use Hendry's own terminology, the information lost in reducing the DGP to its adopted representation, given by the reduced form, must be irrelevant to the problem at hand. Adequacy of the statistical model is evaluated by analyzing the reduced form, i.e. by checking statistical identification. Therefore, the prominence of the structural model, with respect to the reduced form representation, is reversed. The LSE approach starts its specification and identification procedure with a general dynamic reduced form model. The congruency of such a model cannot be directly assessed against the true DGP, which is unobservable. However, model evaluation is made possible by applying the general principle that congruent models should feature truly random residuals; hence, any departure of the vector of residuals from a random normal multivariate distribution should signal a misspecification. Stationarity of the statistical model is a crucial feature when the model has to be simulated. Non-stationarity in macroeconomic time-series is treated in the LSE methodology by reparameterizing the reduced form VAR as a cointegrated VAR. This is achieved by imposing rank reduction restrictions on the matrix determining the long-run equilibria of the system and by solving the identification problem 
of cointegrating vectors (see Johansen, 1995). Once the baseline model has been validated, the reduction process begins by simplifying the dynamics and reducing the dimensionality of the model by omitting the equations for those variables for which the null hypothesis of exogeneity is not rejected. Different tests are proposed for the different concepts of exogeneity by Engle, Hendry and Richard (1983) and even the validity of the Lucas-critique becomes a testable concept (Engle and Hendry (1993), Hendry (1988)). The product of the process of reduction is a statistical model for the data, possibly discriminating between short-run dynamics and long-run equilibria. Only after this validation procedure can the structural model be identified and estimated. A just-identified specification does not require any further testing, as its implicit reduced form does not impose any further restrictions on the baseline statistical model. The validity of the over-identified specification is, instead, tested by evaluating the restrictions implicitly imposed on the general reduced form. The most popular applications of the general-to-specific specification strategy are in the area of money demand (Baba et al. (1992)) and aggregate consumption expenditure (see, for example, Hendry et al. (1990)). As is well discussed in Fukac and Pagan (2006), the LSE approach was influential in the development of a second generation of large equation models, such as the Canadian model RDX2 (Helliwell et al (1991))- and the MPS model at the Fed (Gramlich (2004)), which, apart from introducing much stronger supply side features with respect to traditional IS-LM models, paid considerable attention to dynamic specification and to the implementation of error correction models. In this type of specification the static solution represented a target to which the decision variable adjusted.

In practice, the LSE approach has almost exclusively concentrated on the statistical diagnosis of the failure of large structural models and has brought more attention to the dynamic specification and the long-run properties of models built in the Cowles Commission tradition and used by policy makers. It has paid much less attention to the possibility of specifying a forward-looking microeconomically founded model consistent with the theory based diagnosis for the failure of traditional Cowles Commission models (an interesting example of this approach can be found in Juselius and Johansen (1999)). In a recent paper Juselius and Franchi (2007) propose to formulate all the basic assumptions underlying a theoretical model as a set of hypotheses on the long-run structure of a cointegrated VAR. They also argue in favour of using an identified cointegrated VAR as a way of structuring the data that offers a number a "sophisticated" stylized facts to be matched by empirically relevant theoretical models.

The idea of constructing empirical models based on the belief that economic theory is most informative about the long-run relationships between the relevant variables has been further developed by Hashem Pesaran and a number of coauthors (see, for example Pesaran and Shin (2002), Garratt et al.(2007)) in the so-called "structural cointegrating VAR approach". This approach is based on testing theory based over-identifying restrictions on the long-run relations to provide a statistically coherent framework for the analysis of the short-run. In practice, the implementation is based on a log-linear VARX model where the baseline VAR model is augmented with weakly exogenous variables, such 
as oil prices or country specific foreign variables. Theory based cointegrating relationships are tested and, whenever not rejected, imposed on the specification. No restrictions are imposed on the short-run dynamics of the model except for the, inevitable, choice of lag length for the VARX. Models are then used to evaluate the effect of policies via generalized impulse response functions (see Pesaran and Shin (1998)) and for forecasting.

\section{Model specification and model diagnostics when structural identification matters.}

The great critiques made clear that questions like 'How should a central bank respond to shocks in macroeconomic variables?' are to be answered within the framework of quantitative monetary general equilibrium models of the business cycle, a DSGE model. The general linear (or linearized around equilibrium) DSGE model takes the following form(see $\operatorname{Sims}(2002))$ :

$$
\boldsymbol{\Gamma}_{0} \mathbf{Z}_{t}=\boldsymbol{\Gamma}_{1} \mathbf{Z}_{t-1}+C+\Psi \epsilon_{t}+\Pi \eta_{t}
$$

where $C$ is a vector of constants, $\epsilon_{t}$ is an exogenously evolving random disturbance, and $\eta_{t}$ is a vector of expectations errors, $\left(E_{t}\left(\eta_{t+1}\right)=\mathbf{0}\right)$, not given exogenously but to be treated as part of the model solution. The forcing processes here are the elements of the vector $\epsilon_{t}$, which contains processes like Total Factor Productivity or policy variables that are not determined by an optimization process. Policy variables set by optimization, typically included in $\mathbf{Z}_{t}$, are naturally endogenous as optimal policy requires some response to current and expected developments of the economy ${ }^{4}$. Expectations at time $t$ for some of the variables of the systems at time $t+1$ are also included in the vector $\mathbf{Z}_{t}$ whenever the model is forward looking. Models like (6) can be solved using standard numerical techniques (see, for example, Sims, 2002), and the solution can be expressed as:

$$
\mathbf{Z}_{t}=\mathbf{A}_{0}+\mathbf{A}_{1} \mathbf{Z}_{\mathbf{t}-\mathbf{1}}+\mathbf{R} \epsilon_{t}
$$

where the matrices $\mathbf{A}_{0}, \mathbf{A}_{1}$, and $\mathbf{R}$ contain convolutions of the underlying structural model parameters. Note that the solution is naturally represented as a VAR. In fact, it is a VAR potentially with stochastic singularity, as the dimension of the vector of shocks is typically smaller than that of the vector of variables included in the VAR. However, this problem is promptly solved by adding the appropriate number of measurement errors ${ }^{5}$. Canonical RBC models (see, for example, Kydland and Prescott (1982), and King, Plosser and Rebelo (1988))

\footnotetext{
${ }^{4}$ See Appendix 1 for an example of this representation applied to a simple macroeconomic model.

${ }^{5}$ Expressing the solution of a DSGE as a VAR might also involve solving some non invertibility problems of the matrix governing the simultaneous relation among variables originally considered in the theoretical model. This problem is carefully discussed in the chapter of this volume by Fabio Canova (2007).
} 
contained a limited number of parameters, and within this class of models the role of estimation was clearly de-emphasized and parameters have been often calibrated rather than estimated.

Calibration is extensively described in Cooley (1997). The aim of calibration is not to provide a congruent representation of the data, but simply to find values for the structural parameters of the model that are jointly compatible with the theory and the data in particular well-specified dimensions. The main difference between calibration and standard econometrics lies in the bidirectional relationship between theory and measurement that characterizes the former (see Favero (2001)). Cooley (1995, p. 60) states very clearly that in the calibration approach data and measurement are concepts determined by the features of the theory. The empirics of calibration proceeds in several stages.

First, a preliminary, non-theoretical, inspection of the data identifies some general stylized facts that any economic model should internalize. The theoretical framework at hand, then, integrated by these observed stylized facts, generates the parametric class of models to be evaluated. Once a particular model has been developed, it precisely defines the quantities of interest to be measured, and suggests how available measurements have to be reorganized if they are inconsistent with the theory.

Then, measurements are used to give empirical content to the theory, and in particular to provide empirically based values for the unknown parameters. They are chosen, according to Cooley (1997: 58), by specifying first some features of the data for the model to reproduce ${ }^{6}$ and then by finding some one-toone relationship between these features and the deep parameters of the model. Finally, this relationship is inverted to determine the parameter values that make the model match the observed features.

From this point of view, calibration can be interpreted as a method of moments estimation procedure that focuses on a limited parameter subset, setting only the discrepancy between some simulated and observed moments to zero. Christiano and Eichenbaum (1992) generalize this idea and propose a variant of Hansen's (1982) GMM procedure to estimate and assess stochastic general equilibrium models using specific moments of the actual data. These procedures are formal developments of the basic methodological approach, and share with standard calibration the focus on a limited set of previously selected moments, while standard econometric methods use, in principle, the whole available information set, weighting different moments exclusively according to how much information on them is contained in the actual data, as, for example, in maximum likelihood methods.

Generally, not all parameters can be calibrated, simply because there are more unknown parameters than invertible relationships. A subset of them has to be left to more standard econometric techniques.

Once a parameterization is available, the model is simulated and different kinds of numerical exercises are performed. At this stage model evaluation can also be implemented. Model evaluation was initially conducted by assessing the

\footnotetext{
${ }^{6}$ Importantly, these features ought to be different from those under examination.
} 
ability of the model to reproduce some particular features (of course, ones that are different from those used to calibrate it) of the data. The metric chosen to compare the observed properties and the simulated ones is a critical issue. In the traditional calibration procedure, an informal, 'aesthetic', metric is used, based on the comparison between simulated and observed moments of the relevant variables (see, for example, Kydland and Prescott (1996: 75)). Moreover, as DSGE models are usually solved by linearizing them around equilibrium, raw data cannot be used to generate the set of statistics relevant for model evaluation. Raw data contain trends, so they are usually de-trended using filtering techniques before using them to generate the relevant statistics ${ }^{7}$.

Model Evaluation in DSGE models became much more sophisticated when the practice started to exploit the fact that a solved DSGE model is a VAR.

If we re-partition the vector of variables included in the VAR into macroeconomic and policy variables $\left[\begin{array}{cc}\mathbf{Y}_{t} & \mathbf{M}_{t}\end{array}\right]$, the solved DSGE model could be represented as a Structural VAR:

$$
\mathbf{A}\left(\begin{array}{c}
\mathbf{Y}_{t} \\
\mathbf{M}_{t}
\end{array}\right)=\mathbf{C}(L)\left(\begin{array}{c}
\mathbf{Y}_{t-1} \\
\mathbf{M}_{t-1}
\end{array}\right)+\mathbf{B}\left(\begin{array}{c}
\boldsymbol{\nu}_{t}^{Y} \\
\boldsymbol{\nu}_{t}^{M}
\end{array}\right)
$$

Within this framework a new role for empirical analysis emerges: to provide evidence on the stylized facts to include in the theoretical model adopted for policy analysis and to decide between competing DSGE models. The operationalization of this research program in the case of the analysis of monetary policy is very well described in a paper by Christiano, Eichenbaum and Evans (1998). There are three relevant steps:

1. monetary policy shocks are identified in actual economies, i.e. in a VAR without theoretical restrictions;

2. the response of relevant economic variables to monetary shocks is then described;

3. finally, the same experiment is performed in the model economies to compare actual and model-based responses as an evaluation tool and a selection criterion for theoretical models.

The identification of the shocks of interest is the first and most relevant step in VAR-based model evaluation. VAR modelling recognizes that identification and estimation of structural parameters is impossible without explicitly modelling expectations, therefore a structure like (7) can only be used to run special experiments that do not involve simulating different scenarios for the parameters of interests. A natural way to achieve these results is to experiment with the shocks $\boldsymbol{\nu}_{t}^{M}$. Facts are then provided by looking at impulse response

\footnotetext{
${ }^{7}$ Some abuses of this practice are present in the literature, the most common one is to compare the properties of filtered raw data with those of filtered model generated data. Filtering model generated data is clearly hard to justify given that model generated data are stationary by their nature.
} 
analysis, variance decompositions and historical decompositions. Impulse response analysis describes the effect over time of a policy shock on the variables of interest, variance decomposition illustrates how much of the variance of the forecasting errors for macroeconomic variables at different horizons can be attributed to policy shocks, and historical decomposition allows the researcher to evaluate the effect of zeroing policy shocks on the variables to interest. All these experiments are run by keeping estimated parameters unaltered. Importantly, running these experiments is easier if shocks to the different variables included in the VAR are orthogonal to each other, otherwise it would not be possible to simulate a policy shock by maintaining all the other shocks at zero. As a consequence, VAR models need a structure because orthogonal shocks are normally not a feature of the statistical model. This fact generates an identification problem. In the reduced form we have:

$$
\left(\begin{array}{c}
\mathbf{Y}_{t} \\
\mathbf{M}_{t}
\end{array}\right)=\mathbf{A}^{-1} \mathbf{C}(L)\left(\begin{array}{c}
\mathbf{Y}_{t-1} \\
\mathbf{M}_{t-1}
\end{array}\right)+\left(\begin{array}{c}
\mathbf{u}_{t}^{Y} \\
\mathbf{u}_{t}^{M}
\end{array}\right)
$$

where $\mathbf{u}$ denotes the VAR residual vector, normally and independently distributed with full variance-covariance matrix $\boldsymbol{\Sigma}$. The relation between the residuals in $\mathbf{u}$ and the structural disturbances in $\boldsymbol{\nu}$ is therefore:

$$
\mathbf{A}\left(\begin{array}{c}
\mathbf{u}_{t}^{Y} \\
\mathbf{u}_{t}^{M}
\end{array}\right)=\mathbf{B}\left(\begin{array}{c}
\boldsymbol{\nu}_{t}^{Y} \\
\boldsymbol{\nu}_{t}^{M}
\end{array}\right) .
$$

Undoing the partitioning, we have

$$
\mathbf{u}_{t}=\mathbf{A}^{-1} \mathbf{B} \boldsymbol{v}_{t}
$$

from which we can derive the relation between the variance-covariance matrices of $\mathbf{u}_{t}$ (observed) and $\boldsymbol{\nu}_{t}$ (unobserved) as follows:

$$
E\left(\mathbf{u}_{t} \mathbf{u}_{t}^{\prime}\right)=\mathbf{A}^{-1} \mathbf{B} E\left(\boldsymbol{v}_{t} \boldsymbol{v}_{t}^{\prime}\right) \mathbf{B}^{\prime} \mathbf{A}^{-1} .
$$

Substituting population moments with sample moments we have:

$$
\widehat{\sum}=\widehat{\mathbf{A}}^{-1} \mathbf{B I} \widehat{\mathbf{B}}^{\prime} \widehat{\mathbf{A}}^{-1}
$$

$\widehat{\sum}$ contains $n(n+1) / 2$ different elements, so this is the maximum number of identifiable parameters in matrices $\mathbf{A}$ and $\mathbf{B}$. Therefore, a necessary condition for identification is that the maximum number of parameters contained in the two matrices equals $n(n+1) / 2$, and such a condition makes the number of equations equal to the number of unknowns in system (9). As usual, for such a condition also to be sufficient for identification, no equation in (9) should be a linear combination of the other equations in the system (see Amisano and Giannini 1996, Hamilton 1994). As for traditional models, we have the three possible cases of under-identification, just-identification and over-identification. The validity of over-identifying restrictions can be tested via a statistic distributed 
as a $\chi^{2}$ with the number of degrees of freedom equal to the number of overidentifying restrictions. Once identification has been achieved, the estimation problem is solved by applying generalized method of moments estimation.

Since VAR models are used to discriminate between alternative theoretical models of the economy, it then becomes crucial to identify policy actions using restrictions independent from the theoretical models of the transmission mechanism under empirical investigation, taking into account the potential endogeneity of policy instruments. Restrictions based on the theoretical predictions of models are clearly inappropriate, and so are the Cowles Commission type of restrictions as they do not acknowledge the endogeneity of systematic policy. The recent literature on the monetary transmission mechanism (see Strongin (1995), Bernanke and Mihov (1995), Christiano, Eichenbaum and Evans (1996), Leeper, Sims and Zha (1996)), offers good examples on how these kind of restrictions can be derived. VARs of the monetary transmission mechanism are specified on six variables, with the vector of macroeconomic non-policy variables including gross domestic product (GDP), the consumer price index $(\mathrm{P})$ and the commodity price level $(\mathrm{Pcm})$, while the vector of policy variables includes the federal funds rate $(\mathrm{FF})$, the quantity of total bank reserves (TR) and the amount of non-borrowed reserves (NBR). Given the estimation of the reduced form VAR for the six macro and monetary variables, a structural model is identified by: $(i)$ assuming orthogonality of the structural disturbances; $(i i)$ requiring that macroeconomic variables do not simultaneously react to monetary variables, while simultaneous feedback in the other direction is allowed, and (iii) imposing restrictions on the monetary block of the model reflecting the operational procedures implemented by the monetary policy-maker. All identifying restrictions satisfy the criterion of independence from specific theoretical models. In fact, within the class of models estimated on monthly data, restrictions $(i i)$ are consistent with a wide spectrum of alternative theoretical structures and imply a minimal assumption on the lag of the impact of monetary policy actions on macroeconomic variables, whereas restrictions (iii) are based on institutional analysis. Restrictions (ii) are made operational by setting to zero an appropriate block of elements of the A matrix. Note that restrictions on the contemporaneous feedbacks among variables is not the only way of imposing restrictions consistent with a wide spectrum of theoretical models. In fact, such an aim could be achieved by imposing restrictions on the long-run effects of shocks (for example, there is a clear consensus among macroeconomists that demand shocks have zero effect on output in the long-run) or on the shape of some impulse response functions. These types of restrictions are easily imposed on the SVAR (see, for example, Blanchard-Quah (1989) and Uhlig (1997)), although one must always be aware of the effect of imposing invalid restrictions on parameter estimates (Faust and Leeper (1997)). Finally, note that partial identification can easily be implemented in a VAR model. If the relevant dimension for model comparison is the response of the economy to monetary policy shocks, then there is no need to identify the non-monetary structural shocks in the model. 


\subsection{VAR based model evaluation: an assessment.}

VAR based model evaluation can be assessed by first discussing the results achieved and their impact on model building, and then offering some considerations on the specification of the VAR and on the evaluation of the statistical model adopted.

The main results of the VAR based evaluation model is that, in order to match fluctuations in the data, any model must feature some attrition that causes temporary but rather persistent deviations from the long-run equilibrium defined by a frictionless neoclassical economy. In a series of recent papers, Christiano, Eichenbaum and Evans (1996 a, b) apply the VAR approach to derive 'stylized facts' on the effect of a contractionary policy shock, and conclude that plausible models of the monetary transmission mechanism should be consistent at least with the following evidence on price, output and interest rates: (i) the aggregate price level initially responds very little; (ii) interest rates initially rise, and (iii) aggregate output initially falls, with a $j$-shaped response, and a zero long-run effect of the monetary impulse. Such evidence leads to the dismissal of traditional real business cycle models, which are not compatible with the liquidity effect of monetary policy on interest rates, and of the Lucas (1972) model of money, in which the effect of monetary policy on output depends on price misperceptions. The evidence seems to be more in line with alternative interpretations of the monetary transmission mechanism based on sticky prices models (Goodfriend and King, (1997)), limited participation models (Christiano and Eichenbaum (1992)) or models with indeterminacy-sunspot equilibria (Farmer (1997)). When models are extended to analyze the components of output more frictions need to be added to explain the dynamics of consumption and investment: typically some habit persistence is needed to explain fluctuations in consumption and some adjustment costs are needed to match the dynamics of investment and the stock of capital in the data.

Specification of the VAR and its statistical adequacy is an issue that has not received much explicit attention in the literature. It seems that the choice of the variables included in the VAR is driven by the theoretical model. This is natural: if the theoretical model is a restricted VAR, the natural benchmark is the same VAR without restrictions. But what about potential misspecification of the statistical model?

Statistical analysis of the unrestricted VAR is rather rare, although some implicit consideration has clearly been devoted to this issue. Think, for example, of the "liquidity puzzle" and the "price puzzle" for models of the monetary transmission mechanism.

VAR models of the monetary transmission mechanism were initially estimated on a rather limited set of variables, i.e. prices, money and output, and identified by imposing a diagonal form on the matrix $\mathbf{B}$ and a lower triangular form on the matrix $\mathbf{A}$, with money coming last in the ordering of the variables included in the VAR (Choleski identification). The typical impulse responses obtained within this type of model show that prices slowly react to monetary policy, output responds in the short run, in the long run (from two 
years after the shock onwards) prices start adjusting and the significant effect on output vanishes. There is no strong evidence for the endogeneity of money. Macroeconomic variables play a very limited role in explaining the variance of the forecasting error of money, while money instead plays an important role in explaining fluctuations of both the macroeconomic variables.

Sims (1980) extended the VAR to include the interest rate on Federal funds, ordered just before money as a penultimate variable in the Choleski identification. The idea is to assess the robustness of the above results after identifying the part of money which is endogenous to the interest rate. Impulse response functions and Forecast Errror Variance Decomposition (FEVD) raise a number of issues.

1. Though little of the variation in money is predictable from past output and prices, a considerable amount becomes predictable when past short-term interest rates are included in the information set.

2. It is difficult to interpret the behaviour of money as driven by money supply shocks. The response to money innovations gives rise to the 'liquidity puzzle': the interest rate initially declines very slightly in response to a money shock and then starts increasing afterwards.

3. There are also difficulties with interpreting shocks to interest rates as monetary policy shocks. The response of prices to an innovation in interest rates gives rise to the 'price puzzle': prices increase significantly after an interest rate hike. An accepted interpretation of the liquidity puzzle relies on the argument that the money stock is dominated by demand rather than supply shocks. Moreover, the interpretation of money as demand shocks driven is consistent with the impulse response of money to interest rates. Note also that, even if the money stock were to be dominated by supply shocks, it would reflect both the behaviour of central banks and the banking system. For both these reasons the broad monetary aggregate has been substituted by narrower aggregates, bank reserves, on which it is easier to identify shocks mainly driven by the behaviour of the monetary policy maker. The 'price puzzle' has been attributed to the misspecification of the four-variables VAR used by Sims. Suppose that there exists a leading indicator for inflation to which the Fed reacts. If such a leading indicator is omitted from the VAR, then we have an omitted variable positively correlated with inflation and interest rates. Such omission makes the VAR mis-specified and explains the positive relation between prices and interest rates observed in the impulse response functions. It has been observed (see Christiano, Eichenbaum and Evans (1996), Sims (1996)) that the inclusion of a Commodity Price Index in the VAR solves the 'price puzzle'.

As a result of these developments, a consensus was reached on the specification of the VAR to provide facts on the monetary transmission mechanism (MTM) as a model including prices, output, a commodity price index, the policy 
rate and the narrow money indicators necessary to model the market for bank reserves.

Note that the final specification is very different from the initial one and the modifications in the specification are driven by a number of puzzles found in the impulse responses of discarded VARs. One can, of course, interpret these puzzles as signals of misspecification of the VAR, but it is not clear that puzzles are the best way to diagnose misspecification of the statistical model. Think, for example, of the recent practice of identifying shocks by imposing constraints on the shape of the impulse response functions. It might well be regarded as reasonable to assume that a monetary policy restriction has a non-positive effect on inflation. Obviously, if VARs of the MTM would have always been identified by imposing this restriction, then the price puzzle would never have been observed and one is left to wonder if the consensus specification of the VAR to analyze the MTM would have evolved differently from what it did.

Another issue of crucial importance is structural stability of the parameters estimated in the VAR. If the VAR is a reduced form of a forward-looking model it is of crucial importance to estimate its parameters on a single regime. Although this issue has been explicitly recognized in some papers, for example Bernanke and Mihov (1998), the consensus VAR is normally estimated on a sample including different monetary regimes. The main justification for this practice is that monetary policy shocks are robust to the different identifications generated by the different monetary policy regimes. Some authors have been left skeptical by such robustness and some criticisms have been made of VAR based monetary policy shocks. Rudebusch, (1998) argues that VAR based monetary shocks do not make sense as they are very weakly correlated with monetary policy shocks directly derived from asset prices (the federal fund future). The mainstream reaction to this criticism is that, even if the two type of shocks are very weakly correlated, the impulses responses of macroeconomic variables to VAR based and financial market based monetary policy shocks are not significantly different from each other. Rudebusch's criticism has shared the same fate as other criticisms of the VAR approach. Lippi and Reichlin (1993) pointed out that a crucial assumption in structural VAR modelling is that structural shocks are linear combinations of the residuals in reduced form VAR models, so that modern macroeconomic models which are linearized into dynamic systems tend to include non-invertible moving average components and structural shocks are therefore not identifiable. In fact, the linearized modern macroeconomic models of the monetary transmission mechanism deliver short VARs. In such models structural shocks are combinations of the residuals in the reduced form VARs (the Wold innovations) and the Lippi-Reichlin critique does not seem to be applicable (for a further discussion of this point see Amisano and Giannini (1996)).

To sum up, although the original idea of the Cowles Commission to use the implied unrestricted reduced form as a benchmark to evaluate the structural model is clearly reflected in the VAR based evaluation of DSGE models, the potential importance of the formal evaluation of the adequacy of the statistical model adopted has certainly not received the same attention. However, in the 
practice of VAR specification some attention to the issue of potential misspecification has clearly been paid, although such attention has been more related to the economic interpretation of results than to the implementation of formal statistical criteria for model evaluation.

\section{From VAR based model evaluation to Bayesian analysis of DSGE models.}

VAR based evaluation of early DSGE models made clear that a large number of nominal and real frictions should be added to the traditional new-classical RBC models to replicate relevant features in observed data (see, for example, Christiano, Eichenbaum and Evans, 2005). Adding frictions implies increasing the number of parameters, especially along the dimension of parameters little related to theory. As a consequence, calibration became impractical for attributing numerical values to the DSGE parameters and estimation came back into fashion. However, estimating DSGE models by classical maximum likelihood methods proved to be very hard, as the convergence of the estimates to values that ensure a unique stable solution turned out to be practically impossible to achieve when implementing unconstrained maximum likelihood estimation. A paper by Ireland (2004) made an exception and obtained convergence of numerical estimates of parameters of a DSGE model to values that allow economic policy simulation. In fact, the Ireland method consists of penalizing the likelihood function along some dimension so that the range of variation of many parameters is limited (for an interesting discussion of the estimation implemented in Ireland, see Johansen (2004)).

In practice, one can think of Ireland's method as a naive Bayesian one in which some form of (very tight) prior is imposed on ( at least a subset of) the parameters. A natural development of Ireland's proposal was to extend the naive Bayesian framework to a proper Bayesian framework. This is what happened as soon as the use of MCMC methods to derive the relevant posterior distribution of parameters became widespread (see An and Schorfeide (2005) Del Negro, Smets and Wouters (2003) and Ruge-Murcia (2003) for surveys and applications).

Once adopted, the Bayesian framework offered naturally some new possibilities of integrating theoretical and empirical models. Originally this interaction was proposed as a set of modern model evaluation tools. These were generated by pairing the tradition of model evaluation in the Bayesian approach to macroeconometrics with the VAR nature of a solved DSGE model.

The Bayesian approach made its way into applied macroeconometrics to solve the problem of the lack of parsimony of VARs. In practice, data availability from a single regime poses a binding constraint on the number of variables and the number of lags that can be included in a VAR without overfitting the data. A solution of the problem of over-parameterization is to constrain the parameters by shrinking them toward some specific point in the parameter space. 
The Minnesota prior, proposed by Doan, Litterman and Sims (1984), uses the Bayesian approach to shrink the estimates toward the univariate random walk representation for all variables included in the VAR. Within this framework, Bayesian methods are used to save degrees of freedom on the basis of the well established statistical evidence that no-change forecasts are known to be very hard to beat for many macroeconomic variables. De Jong, Ingram and Whiteman $(1996,2000)$ and Ingram and Whiteman (1994) proposed evaluating RBC models by comparing the forecasting performance of a Bayesian VAR estimated via the Minnesota prior with that of a VAR in which the atheoretical prior information in the Minnesota prior was supplanted by the information in a RBC model.

In a series of papers, Del Negro and Schorfeide (2004, and 2006) and Del Negro, Schorfeide, Smets and Wouters (2004) use this approach to develop a model evaluation method that tilts coefficient estimates of an unrestricted VAR toward the restriction implied by a DSGE model. The weight placed on the DSGE model is controlled by a hyperparameter called $\lambda$. This parameter takes values ranging from 0 (no-weight on the DSGE model) to $\infty$ (no weight on the unrestricted VAR). Therefore, the posterior distribution of $\lambda$ provides an overall assessment of the validity of the DSGE model restrictions. To see how the approach is implemented, consider that the solved DSGE model generates a restricted MA representation for the vector of $n$ variables of interest, $\mathbf{Z}_{t}$ $=\left(\begin{array}{ll}\mathbf{Y}_{t} & \mathbf{M}_{t}\end{array}\right)$, that can be approximated by a VAR of order $p$ :

$$
\begin{aligned}
\mathbf{Z}_{t} & =\boldsymbol{\Phi}_{0}^{*}(\theta)+\mathbf{\Phi}_{1}^{*}(\theta) \mathbf{Z}_{t-1}+\ldots+\mathbf{\Phi}_{p}^{*}(\theta) \mathbf{Z}_{t-p}+\mathbf{u}_{t}^{*} \\
\mathbf{u}_{t}^{*} & \sim N\left(\mathbf{0}, \Sigma_{u}^{*}(\theta)\right) \\
\mathbf{Z}_{t}^{\prime} & =\mathbf{X}_{t}^{\prime} \mathbf{\Phi}^{*}(\theta)+\mathbf{u}_{t}^{\prime} \\
\mathbf{X}_{t} & =\left[1, \mathbf{Z}_{t-1}^{\prime}, \ldots, \mathbf{Z}_{t-p}^{\prime}\right] \\
\mathbf{\Phi}^{*}(\theta) & =\left[\boldsymbol{\Phi}_{0}^{*}(\theta), \boldsymbol{\Phi}_{1}^{*}(\theta), \ldots, \boldsymbol{\Phi}_{p}^{*}(\theta)\right]^{\prime}
\end{aligned}
$$

where all coefficients are convolutions of the structural parameters in the model included in the vector $\theta$. The chosen benchmark to evaluate this model is the unrestricted VAR derived from the solved DSGE model

$$
\begin{aligned}
\mathbf{Z}_{t}^{\prime} & =\mathbf{X}_{t}^{\prime} \boldsymbol{\Phi}+\mathbf{u}_{t}^{\prime}, \\
\mathbf{\Phi} & =\left[\boldsymbol{\Phi}_{0}, \boldsymbol{\Phi}_{1}, \ldots, \boldsymbol{\Phi}_{p}\right]
\end{aligned}
$$

where:

$$
\begin{aligned}
\boldsymbol{\Phi} & =\boldsymbol{\Phi}^{*}(\theta)+\boldsymbol{\Phi}^{\Delta} \\
\Sigma_{u} & =\Sigma_{u}^{*}(\theta)+\Sigma_{u}^{\Delta} .
\end{aligned}
$$

The DSGE restrictions are imposed on the VAR by defining: 


$$
\begin{aligned}
\Gamma_{X X}(\theta) & =E_{\theta}^{D}\left[\mathbf{X}_{t} \mathbf{X}_{t}^{\prime}\right] \\
\Gamma_{X Z}(\theta) & =E_{\theta}^{D}\left[\mathbf{X}_{t} \mathbf{Z}_{t}^{\prime}\right]
\end{aligned}
$$

where $E_{\theta}^{D}$ defines the expectation with respect to the distribution generated by the DSGE model. Such distribution needs to be well defined. We then have:

$$
\boldsymbol{\Phi}^{*}(\theta)=\Gamma_{X X}(\theta)^{-1} \Gamma_{X Z}(\theta)
$$

Beliefs about the DSGE model parameters $\theta$ and model misspecification matrices $\boldsymbol{\Phi}^{\Delta}$ and $\Sigma_{u}^{\Delta}$ are summarized in prior distributions, that, as shown in Del Negro et al.(2004), can be transformed into priors for the VAR parameters $\Phi$ and $\Sigma_{u}$. In particular we have:

$$
\begin{aligned}
\Sigma_{u} \mid \theta & \sim I W\left(\lambda T \Sigma_{u}^{*}(\theta), \lambda T-k, n\right) \\
\mathbf{\Phi} \mid \Sigma_{u}, \theta & \sim N\left(\boldsymbol{\Phi}^{*}(\theta), \frac{1}{\lambda T}\left[\Sigma_{u}^{-1} \otimes \Gamma_{X X}(\theta)\right]^{-1}\right)
\end{aligned}
$$

where the parameter $\lambda$ controls the degree of model misspecification with respect to the VAR: for small values of $\lambda$ the discrepancy between the VAR and the DSGE-VAR is large and a sizeable distance is generated between unrestricted VAR and DSGE estimators, large values of $\lambda$ correspond to small model misspecification and, for $\lambda=\infty$, beliefs about DSGE misspecification degenerate to a point mass at zero. Bayesian estimation could be interpreted as estimation based on a sample in which data are augmented by a hypothetical sample in which observations are generated by the DSGE model; within this framework $\lambda$ determines the length of the hypothetical sample.

Given the prior distribution, posteriors are derived by Bayes theorem:

$$
\begin{aligned}
\Sigma_{u} \mid \theta, Z & \sim I W\left((\lambda+1) T \hat{\Sigma}_{u, b}(\theta),(\lambda+1) T-k, n\right) \\
\mathbf{\Phi} \mid \Sigma_{u}, \theta, Z & \sim N\left(\hat{\mathbf{\Phi}}_{b}(\theta), \Sigma_{u} \otimes\left[\lambda T \Gamma_{X X}(\theta)+\mathbf{X}^{\prime} \mathbf{X}\right]^{-1}\right) \\
\hat{\mathbf{\Phi}}_{b}(\theta) & =\left(\lambda T \Gamma_{X X}(\theta)+\mathbf{X}^{\prime} \mathbf{X}\right)^{-1}\left(\lambda T \Gamma_{X Z}(\theta)+\mathbf{X}^{\prime} \mathbf{Z}\right) \\
\hat{\Sigma}_{u, b}(\theta) & =\frac{1}{(\lambda+1) T}\left[\left(\lambda T \Gamma_{Z Z}(\theta)+\mathbf{Z}^{\prime} \mathbf{Z}\right)-\left(\lambda T \Gamma_{X Z}(\theta)+\mathbf{X}^{\prime} \mathbf{Z}\right) \hat{\mathbf{\Phi}}_{b}(\theta)\right]
\end{aligned}
$$

which shows that the smaller $\lambda$, the closer the estimates are to the OLS estimates of an unrestricted VAR, the higher $\lambda$ the closer the estimates are to the values implied by the DSGE model parameters $\theta$.

In practice, a grid search is conducted on a range of values for $\lambda$ to choose that value which maximizes the marginal data density. The typical results obtained when using DSGE-VECM $(\lambda)$ to evaluate models with frictions is that 
" ... the degree of misspecification in large-scale DSGE models is no longer so large as to prevent their use in day-to-day policy analysis, yet is not small enough that it can be ignored...".

\subsection{DSGE-VAR analysis: an assessment}

If we consider the DSGE-VAR approach to be a model evaluation tool we observe that it takes the Lucas and Sims critique very seriously but it ignores the issue of specification of the statistical model. The VAR used as a benchmark is the solved DSGE model that is generalized only by relaxing restrictions on parameters. The validity of the statistical model underlying the empirical specification is never questioned. Although the models are different, the evaluation strategy in the DSGE-VAR approach is very similar to the approach of evaluating models by testing over-identifying restrictions without assessing the statistical model, as implemented in Cowles Commission models. In fact, the DSGE-VAR approach is looser than that of the Cowles Commission approach as model based restrictions are not imposed and tested but a different question is asked: restrictions are made fuzzy by imposing a distribution on them. Withins this approach the relevant question becomes what is the amount of uncertainty that we have to add to model based restrictions in order to make them compatible not with the data but with a model-derived unrestricted VAR representation of the data. The natural question here is how well does this procedure do in rejecting false models? Spanos (1991) has shown clearly that modification of the structure of the statistical model could lead to dramatic changes in the outcome of tests for over-identifying restrictions. Why is this worry so strongly de-emphasized in the DSGE-VAR literature?

What are the potential sources of model derived VAR misspecification? An obvious candidate are all those variables that are related to the misspecification of the theoretical model, but there are also all those variables that are not theory related but are important to model the actual behaviour of policy makers. Think, for example, of the commodity price index and the modelling of the behaviour of the monetary policy authority. We have discussed in the previous section how the inclusion of this variable in a VAR to identify monetary policy shocks has been deemed important to model correctly the information set of the monetary policy maker when forecasting inflation and then to fix the "pricepuzzle". DSGE models do not typically include the commodity price index in their specification, and as a consequence the VAR derived by relaxing the theoretical restrictions in a DSGE model is misspecified. Thus the evaluation of the effects of conducting model misspecification with a "wrong" benchmark is a practically relevant one.

As a matter of fact, DSGE models tend to produce a high number of very persistent shocks (see Smets and Wouters, 2003), and this would have certainly been taken as a signal of model misspecification by an LSE type methodology. Still, the models do not do too badly when judged by the metric of the $\lambda$ test. It would be important to have some evaluation of phenomena like this.

Another dimension potentially relevant for evaluating the statistical model 
underlying the VAR-DSGE is the structural stability of the VAR parameters. If the DSGE restrictions are valid, then parameters in the VAR are convolutions of structural parameters that, by their nature, should be constant over time. It is well known that tests for structural stability have problems of power, especially in the presence of multiple breaks at unknown dates. Detecting structural breaks in parameters of interest becomes even harder when structural innovations in the DSGE are allowed to have volatilities that vary over time. Justiniano and Primiceri (2005) have extended the Bayesian framework to develop an algorithm for inferring DSGE model parameters and time varying volatilities of structural shocks. Allowing for time varying volatilities makes the DSGE model consistent with structural breaks while keeping the deep parameters constant. However, it is hard to distinguish empirically the case for genuine stochastic volatility against a situation in which allowing for stochastic volatility in the estimation picks up parameter instability in a VAR model with constant volatility of structural shocks (see Benati and Surico(2007).

There are alternatives to the use of a VAR as a benchmark. The limited information problem of VARs could be solved by combining traditional VAR analysis with recent developments in factor analysis for large data sets and using a factor-augmented VAR (FAVAR) as the relevant statistical model to conduct model evaluation. A recent strand of the econometric literature ${ }^{8}$ has shown that very large macroeconomic datasets can be properly modelled using dynamic factor models, where the factors can be considered as an exhaustive summary of the information in the data. This approach has been successfully employed to forecast macroeconomic time series and, in particular, inflation. As a natural extension of the forecasting literature, Bernanke and Boivin (2003), and Bernanke, Boivin and Eliasz (2005) proposed to exploit these factors in the estimation of VARs. A FAVAR benchmark for the evaluation of a DSGE model will take the following specification:

$$
\left(\begin{array}{c}
\mathbf{Z}_{t} \\
\mathbf{F}_{t}
\end{array}\right)=\left[\begin{array}{ll}
\boldsymbol{\Phi}_{11}(L) & \boldsymbol{\Phi}_{12}(L) \\
\boldsymbol{\Phi}_{21}(L) & \boldsymbol{\Phi}_{22}(L)
\end{array}\right]\left(\begin{array}{c}
\mathbf{Z}_{t-1} \\
\mathbf{F}_{t-1}
\end{array}\right)+\left(\begin{array}{c}
\mathbf{u}_{t}^{Z} \\
\mathbf{u}_{t}^{F}
\end{array}\right),
$$

where $\mathbf{Z}_{t}$ are the variables included in the DSGE model and $\mathbf{F}_{t}$ is a small vector of unobserved factors extracted from a large data-set of macroeconomic time series that capture additional economic information relevant to model the dynamics of $\mathbf{Z}_{t}$. The system reduces to the standard VAR used to evaluate DSGE models if $\boldsymbol{\Phi}_{12}(L)=0$. Therefore, within this context, the relevant $\lambda$ test would add to the usual DSGE model-related restrictions on $\boldsymbol{\Phi}_{11}(L)$ the restrictions $\boldsymbol{\Phi}_{12}(L)=0$.

Consolo et al. (2007) apply this idea to find that FAVAR models dominate VAR specifications generated by adopting unrestricted versions of the solution of DSGE models. Such dominance is clearly established by analysis of residuals and evaluation of forecasting performance. However, when the Bayesian approach is applied to the DSGE-FAVAR instead of the DSGE-VAR, some support for the DSGE model is still found in the data (the optimal $\lambda$ in the DSGE-FAVAR

${ }^{8}$ Stock and Watson $(2002)$, Forni and Reichlin $(1996,1998)$ and Forni et al. $(1999,2000)$ 
is different from zero). Moreover, the optimal combination of the DSGE model and the statistical model based on a larger information set (the FAVAR) delivers a forecasting model (the DSGE-FAVAR) that dominates all alternatives. This evidence leads to a new interaction between theory and empirical analysis where the theoretical DSGE model should not be considered as a model for the data but as a generator of prior distributions for the empirical model. The use of the FAVAR as an empirical model allows including in the analysis the information that is not considered in the theoretical model.

Besides this application there has been no work using FAVAR to evaluate DSGE. Interestingly what has instead happened is that FAVAR has been interpreted as the reduced form of a DSGE model. This result has been achieved by removing the assumption that economic variables included in a DSGE are properly measured by a single indicator: variables in the theoretical model are considered as as unobservable and the information set in factors is used to map them (Boivin and Giannoni (2005)). This approach makes a FAVAR the reduced form of a DSGE model, although the restrictions implied by the DSGE model on a general FAVAR are very difficult to trace and model evaluation becomes even more difficult to implement. In fact, a very tightly parameterized theory model can have a very highly parameterized reduced form if one is prepared to accept that the relevant theoretical concepts in the model are combinations of many macroeconomic and financial variables. Identification of the relevant structural parameters, which is already very hard in DSGE model with observed variables (see Canova and Sala (2006)), becomes even harder. Natural advantages of this approach are increased efficiency in the estimation of the model and improved forecasting performance. However, model evaluation becomes almost impossible to pursue and a theoretical model can only by rejected by another theoretical model, while the implied statistical model is made so general that it becomes very hard to use theory as a generator of prior distributions and it becomes impossible to use the evidence from the data to reject theory.

\section{What is next?}

The main challenge for the econometrics of monetary policy is the combination of theoretical models and information from the data to construct empirical models. The failure of the large econometric models at the beginning of the 1970s might be explained by their incapability of taking proper account of both these aspects. The great critiques by Lucas and Sims have generated an alternative approach which, at least initially, has been almost entirely dominated by theory. The LSE approach has instead concentrated on the properties of the statistical models and on the best way of incorporating information from the data into the empirical models, paying little attention to the economic foundation of the adopted specification. The realization that the solution of a DSGE model can be approximated by a restricted VAR, which is also a statistical model, has generated a potential link between the two approaches. The open question is which type of VARs are most appropriate for the econometric analysis of monetary 
policy.

At the moment there are a number of alternative answers to this question. A first approach looks at theoretical DSGE models as the natural way to generate prior distributions for the empirical model, which should be an (optimal) combination of a tightly parameterized theoretical model and of a more general empirical model. This approach requires the application of Bayesian methods. A second approach looks at theory as informative only for the long-run relations between economic variables, so theory should be used to specify a cointegrated VAR in which the short-run dynamics are determined by the data but the long-run properties of the model depend on testable (and tested) theoretical assumptions. Importantly, both these answers recognize the importance of both the theoretical and the statistical model, although the relative weights can be very different. Within this framework modelling nonlinearity and structural breaks could be an important development.

The econometrics of monetary policy is now based on models that incorporate a large number of nominal and real frictions to be added to the traditional new-classical RBC models to replicate relevant features in observed data. These models typically incorporate the labour market, consumers and producers behaviour and monetary and fiscal policies, so the next step is probably more accurate and explicit modelling of the interaction between financial markets and product markets. 


\section{Appendix 1: the $\operatorname{Sims}(2002)$ representation of a small macroeconomic model}

Consider a small New Keynesian DSGE model of the economy which features a representative household optimizing over consumption, real money holdings and leisure, a continuum of monopolistically competitive firms with price adjustment costs and a monetary policy authority which sets the interest rate. The model is driven by three exogenous processes which determine government spending, $g_{t}$, the stationary component of technology, $z_{t}$, and the policy shock, $\epsilon_{R, t}$. A full description of the model can be found in Woodford (2003). For the purpose at hand we focus on its log-linear representation which takes each variable as deviations from its trend. The model has a deterministic steady state with respect to the de-trended variables: the common component is generated by a stochastic trend in the exogenous process for technology. The specification follows Del Negro and Schorfheide (2004)(DS) and it reads:

$$
\begin{aligned}
\tilde{x}_{t} & =E_{t} \tilde{x}_{t+1}-\frac{1}{\tau}\left(\tilde{R}_{t}-E_{t} \tilde{\pi}_{t+1}\right)+\left(1-\rho_{G}\right) \tilde{g}_{t}+\rho_{z} \frac{1}{\tau} \tilde{z}_{t} \\
\tilde{\pi}_{t} & =\beta E_{t} \tilde{\pi}_{t+1}+\kappa\left(\tilde{x}_{t}-\tilde{g}_{t}\right) \\
\tilde{R}_{t} & =\rho_{R} \tilde{R}_{t-1}+\left(1-\rho_{R}\right)\left(\psi_{1} \tilde{\pi}_{t}+\psi_{2} \tilde{x}_{t}\right)+\epsilon_{R, t} \\
\tilde{g}_{t} & =\rho_{g} \tilde{g}_{t-1}+\epsilon_{g, t} \\
\tilde{z}_{t} & =\rho_{z} \tilde{z}_{t-1}+\epsilon_{z, t}
\end{aligned}
$$

where $\tilde{x}_{t}$ is the output gap, $\tilde{\pi}_{t}$ is the inflation rate, $\tilde{R}_{t}$ is the short-term interest rate and $\tilde{g}_{t}$ and $\tilde{z}_{t}$ are two stationary $\operatorname{AR}(1)$ processes for government and technology, respectively.

The first equation is an intertemporal Euler equation obtained from the households' optimal choice of consumption and bond holdings. There is no investment in the model and so output is proportional to consumption up to an exogenous process that describes fiscal policy. The net effects of these exogenous shifts on the Euler equation are captured in the process $\tilde{g}_{t}$. The parameter $0<\beta<1$ is the households' discount factor and $\tau>0$ is the inverse of the elasticity of intertemporal substitution. The second equation is the forward-looking Phillips curve which describes the dynamics of inflation and where $\kappa$ determines the degree of the short-run trade-off between output and inflation. The third equation is the monetary policy reaction function. The central bank follows a nominal interest rate rule by adjusting its instrument to deviations of inflation and output from their respective target levels. The shock $\epsilon_{R, t}$ can be interpreted as an unanticipated deviation from the policy rule or as policy implementation error. Fiscal policy is simply described by an autoregressive process. The set of structural shocks is thus $\epsilon_{t}=\left(\epsilon_{R, t}, \epsilon_{g, t}, \epsilon_{z, t}\right)^{\prime}$, which collects technology, government and monetary shocks.

To cast the model in the form of :

$$
\Gamma_{0} \tilde{\mathbf{Z}}_{t}=\Gamma_{1} \tilde{\mathbf{Z}}_{t-1}+C+\Psi \epsilon_{t}+\Pi \eta_{t}
$$


specify the relevant matrices as follows:

$$
\begin{aligned}
& \tilde{\mathbf{Z}}_{t}=\left[\begin{array}{c}
\widetilde{x_{t}} \\
\widetilde{\pi_{t}} \\
\widetilde{R_{t}} \\
\widetilde{R_{t}^{*}} \\
\widetilde{g_{t}} \\
\widetilde{z_{t}} \\
E_{t} \widetilde{x_{t+1}} \\
E_{t} \widetilde{\pi_{t+1}}
\end{array}\right] \quad \epsilon_{t}=\left[\begin{array}{c}
\epsilon_{t}^{R} \\
\epsilon_{t}^{G} \\
\epsilon_{t}^{Z}
\end{array}\right] \quad \eta_{t}=\left[\begin{array}{c}
\eta_{t}^{x}=x_{t}-E_{t-1}\left(x_{t}\right) \\
\eta_{t}^{\pi}=\pi_{t}-E_{t-1}\left(\pi_{t}\right)
\end{array}\right] \\
& \Gamma_{0}=\left[\begin{array}{cccccccc}
1 & 0 & \frac{1}{\tau} & 0 & -\left(1-\rho_{g}\right) & -\frac{\rho_{z}}{\tau} & -1 & -\frac{1}{\tau} \\
-\kappa & 1 & 0 & 0 & \kappa & 0 & 0 & -\beta \\
0 & 0 & 1 & -\left(1-\rho_{R}\right) & 0 & 0 & 0 & 0 \\
-\psi_{2} & -\psi_{1} & 0 & 1 & 0 & 0 & 0 & 0 \\
0 & 0 & 0 & 0 & 1 & 0 & 0 & 0 \\
0 & 0 & 0 & 0 & 0 & 1 & 0 & 0 \\
1 & 0 & 0 & 0 & 0 & 0 & 0 & 0 \\
0 & 1 & 0 & 0 & 0 & 0 & 0 & 0
\end{array}\right] \\
& \Gamma_{1}=\left[\begin{array}{cccccccc}
0 & 0 & 0 & 0 & 0 & 0 & 0 & 0 \\
0 & 0 & 0 & 0 & 0 & 0 & 0 & 0 \\
0 & 0 & \rho_{R} & 0 & 0 & 0 & 0 & 0 \\
0 & 0 & 0 & 0 & 0 & 0 & 0 & 0 \\
0 & 0 & 0 & 0 & \rho_{G} & 0 & 0 & 0 \\
0 & 0 & 0 & 0 & 0 & \rho_{Z} & 0 & 0 \\
0 & 0 & 0 & 0 & 0 & 0 & 1 & 0 \\
0 & 0 & 0 & 0 & 0 & 0 & 0 & 1
\end{array}\right] \\
& \Psi=\left[\begin{array}{lll}
0 & 0 & 0 \\
0 & 0 & 0 \\
1 & 0 & 0 \\
0 & 0 & 0 \\
0 & 1 & 0 \\
0 & 0 & 1 \\
0 & 0 & 0 \\
0 & 0 & 0
\end{array}\right] \quad \Pi=\left[\begin{array}{ll}
0 & 0 \\
0 & 0 \\
0 & 0 \\
0 & 0 \\
0 & 0 \\
0 & 0 \\
1 & 0 \\
0 & 1
\end{array}\right]
\end{aligned}
$$

As a solution to (15), we obtain the following policy function

$$
\tilde{Z}_{t}=T(\theta) \tilde{Z}_{t-1}+R(\theta) \epsilon_{t}
$$

To provide the mapping between the observable data and those computed as deviations from the steady state of the model, we set the following measurement equations, as in DS:

$$
\begin{aligned}
\Delta \ln x_{t} & =\ln \gamma+\Delta \tilde{x}_{t}+\tilde{z}_{t} \\
\Delta \ln P_{t} & =\ln \pi^{*}+\tilde{\pi}_{t} \\
\ln R_{t} & =4\left[\left(\ln R^{*}+\ln \pi^{*}\right)+\tilde{R}_{t}\right]
\end{aligned}
$$


which can also be cast into matrices as:

$$
Y_{t}=\Lambda_{0}(\theta)+\Lambda_{1}(\theta) \tilde{Z}_{t}+v_{t}
$$

where $Y_{t}=\left(\Delta \ln x_{t}, \Delta \ln P_{t}, \ln R_{t}\right)^{\prime}, v_{t}=0$ and $\Lambda_{0}$ and $\Lambda_{1}$ are defined accordingly. For completeness, we write the matrices $T, R, \Lambda_{0}$ and $\Lambda_{1}$ as a function of the structural parameters in the model, $\theta=\left(\ln \gamma, \ln \pi^{*}, \ln r^{*}, \kappa, \tau, \psi_{1}, \psi_{2}, \rho_{R}, \rho_{g}, \rho_{Z}, \sigma_{R}, \sigma_{g}, \sigma_{Z}\right)^{\prime}$ : such a formulation derives from the rational expectations solution.

The evolution of the variables of interest, $Y_{t}$, is therefore determined by (15) and (20), which impose a set of restrictions across the parameters of the moving average (MA) representation. Finally, the MA representation is approximated by a finite order VAR representation.

\section{References}

[1] Amisano, G., and Giannini, C. (1996). Topics in Structural VAR Econometrics. Springer-Verlag.

[2] An, Sungbae, and Frank Schorfheide (2006): "Bayesian Analysis of DSGE Models", Working Paper, 06-5, Federal Reserve Bank of Atlanta.

[3] Anderson, T.W. and H. Rubin (1949) "Estimation of the parameters of a single equation in a complete system of stochastic equations" Annals of Mathematical Statistics 20, 46-63.

[4] Arouba, S.B., J. Fernandez-Villaverde and J.F. Rubio-Ramirez (2003): "Comparing Solution Methods for Dynamic Equilibrium Economies," PIER Working Paper 04-003.

[5] Baba, Y., D.F. Hendry, and R.M. Starr (1992). The demand for M1 in the U.S.A., 1960-1988. Review of Economic Studies, 59, 25-61.

[6] Basmann, R.L. (1960). "On finite sample distributions of generalized classical linear identifiability test statistic." Journal of the American Statistical Association 55. 650-659.

[7] Benati L. and P.Surico(2007) "Var Analysis of the Great Moderation", http://unjobs.org/authors/paolo-surico

[8] Bernanke, Ben S., and Jean Boivin (2003): "Monetary Policy in a DataRich Environment," Journal of Monetary Economics, 50, 525-564.

[9] Bernanke, Ben S., Jean Boivin and Piotr Eliasz (2005): " Measuring the Effects of Monetary Policy a Factor-Augmented Vector Autoregressive (FAVAR) Approach," The Quarterly Journal of Economics, 120, 1, 387422.

[10] Bernanke, B. S. and Mihov, I. (1998). 'Measuring monetary policy'. Quarterly Journal of Economics, 113, 3, 869-902. 
[11] Blanchard, O. J., and Quah, D. T. (1989). 'The dynamic effects of aggregate demand and supply disturbances'. American Economic Review, 79: 655-73.

[12] Blanchard, Oliver, and Charles M. Kahn (1980): " The Solution of Linear Difference Models under Rational Expectation," Econometrica, 48, 13051313.

[13] Boivin, Jean, and Marc P. Giannoni (2005):"DSGE Models in a Data-Rich Environment," Working Paper.

[14] Canova, Fabio (1994): "Statistical Inference in Calibrated Models," Journal of Applied Econometrics, 9, S123-144.

[15] Canova, Fabio, (2007): Methods for Applied Macroeconomic Research, Princeton University Press.

[16] Canova Fabio,(2007) "How much structure in empirical models", Chapter in this volume.

[17] Canova, Fabio and Gianni De Nicolò (2002): "Monetary Disturbances Matter for Business Cycle Fluctuations in the G-7," Journal of Monetary Economics, 49,6, 1131-1159.

[18] Canova, F. and L. Sala (2005) "Back to Square one: identification issues in DSGE models" , IGIER Working Paper 303, Università Bocconi

[19] Clarida, Richard, Jordi Galì, and Mark Gertler (2000): "Monetary Policy Rules and Macroeconomics Stability: Evidence and some Theory," Quarterly Journal of Economics, 115, 147-180.

[20] Christiano, L. J., and Eichenbaum, M. (1992). 'Liquidity Effects and the Monetary Transmission Mechanism'. American Economic Review, 82, 2: 346-353.

[21] Christiano, L. J., Eichenbaum, M., and Evans, C. L. (1996a). 'The Effects of Monetary Policy Shocks: Evidence from the Flow of Funds'. Review of Economics and Statistics, 78, 16-34.

[22] Christiano, L. J., Eichenbaum, M., and Evans, C. L. (1996b). 'Monetary Policy Shocks and their Consequences: Theory and Evidence'. Paper presented at ISOM.

[23] Christiano, L. J., Eichenbaum, M., and Evans, C. L. (1998). 'Monetary Policy shocks: what have we learned and to what end?'. NBER working paper No. 6400.

[24] Christiano, Lawrence, Martin Eichenbaum, and Charles Evans (2005): "Nominal Rigidities and the Dynamic effects of a Shcok to Monetary Policy," Journal of Political Economy, 113, 1-45. 
[25] Cogley, Timothy, and James Nason (1994): "Testing the Implications of Long-Run Neutrality for Monetary Business Cycle Models," Journal of Applied Econometrics, 9, S37-70.

[26] Consolo A., C.A. Favero and A.Paccagnini(2007) "On the Statistical Identification of DSGE models" IGIER Discussion Paper

[27] Cooley, T. F. (1995). Frontiers of Business Cycle Research. Princeton: Princeton University Press.

[28] Cooley, T. F. (1997). 'Calibrated Models'. Oxford Review of Economic Policy, 13: 55-69.

[29] Doan, Thomas, Robert Litterman and Christopher Sims (1984): "Forecasting and Conditional Projections Using Realistic Prior Distributions," Econometric Reviews, 3, 1-100.

[30] DeJong, David, Beth Ingram, and Charles Whiteman (1996):"A Bayesian Approach to Calibration," Journal of Business economics and Statistics, $14,1-9$.

[31] DeJong, David, Beth Ingram, and Charles Whiteman (2000): "A Bayesian Approach to Dynamic Macroeconomics," Journal of Econometrics, 98, 203-223.

[32] Del Negro, Marco, and Frank Schorfheide (2004): " Priors from General equilibrium Models for VARs," International Economic Review, 45, 643673.

[33] Del Negro, Marco, and Frank Schorfheide (2006): "How Good is what You've Got? DSGE-VAR as a Toolkit for evaluating DSGE Models," Federal Reserve Bank of Atlanta Economic Review

[34] Del Negro, Marco, Frank Schorfheide, Frank Smets and Raf Wouters (2006): "On the Fit of New-Keynesian Models," Working Paper.

[35] Engle R., Hendry D.F. and J.F. Richard(1983) "Exogeneity", Econometrica, 51, 277-302

[36] Engle R. and D.F. Hendry(1993) "Testing superexogeneity and invariance in regression models", Journal of Econometrics, 56, 119-139

[37] Faust, Jon (1998): "The Robustness of Identified VAR Conclusions about Money," Carnegie Rochester Conference Series 49 , 207-44.

[38] Faust, J., and Leeper, E. M. (1997). 'When do long run identifying restrictions give reliable results?'. Journal of Business and Economic Statistics, 15, 3: 345-353.

[39] Favero C.A.(2001) Applied Macroeconometrics, Oxford University Press, Oxford 
[40] Fernandez-Villaverde, Jesus, and Juan Francisco Rubio-Ramirez (2004): " Comparing Dynamic Equilibrium Models to Data: A Bayesian Approach," Journal of Econometrics, 123, 1, 153-87.

[41] Forni, M. and L. Reichlin (1996), "Dynamic common factors in large crosssections", Empirical Economics, 21, 27-42.

[42] Forni, M. and L. Reichlin (1998), "Let's get real: A dynamic factor analytical approach to disaggregated business cycle", Review of Economic Studies, 65, 453-474.

[43] Forni, M., Hallin, M., Lippi, M. and L. Reichlin (2000), "The generalized factor model: identification and estimation", The Review of Economic and Statistics.

[44] Fukac M. and A.Pagan(2006), "Issues in adopting DSGE models for the use in policy process", CAMA Working Paper Series

[45] Garratt, A., Lee K., M.H.Pesaran and Y.Shin (2006) "Global and National Macroeconometric Modelling. A Long-run structural approach.", Oxford University Press, Oxford.

[46] Geweke, John (1999): "Using Simulation Methods for Bayesian Econometric Models: Inference, Development, and Communications," Econometrics Reviews, 18, 1-127.

[47] Goldberger, A. S. (1991). A course in econometrics. Cambridge, Massachusetts: Harvard University Press.

[48] Goodfriend, M., and King, R. (1997). 'The Newclassical Synthesis and the Role of Monetary Policy'. Paper presented at the 12th NBER Annual Macroeconomic Conference.

[49] Gramlich, E.M. (2004), "Remarks", paper presented to the Conference on Models and Monetary Policy, Federal Reserve Bank Board of Governors,

[50] Helliwell, J.F., G.R. Sparks, F.W. Gorbet, H.T. Shapiro, I.A. Stewart and D.R. Stephenson (1991), The Structure of RDX2, Bank of Canada Staff Study No. 7

[51] Hendry, D.F.(1988) "The econcompassing implications of feedback versus feedforward mechanisms in econometrics", Oxford Economic Papers,4:133-147.

[52] Hendry, D.F. (1995). Dynamic Econometrics. Oxford: Oxford University Press.

[53] Hendry, D.F., J.N.J. Muellbauer, and T.A. Murphy (1990). The Econometrics of DHSY. In J.D. Hey and D. Winch (Eds.), A Century of Economics, pp. 298-334. Oxford: Basil Blackwell. 
[54] Hendry D.F. and G.E. Mizon(1991?) "Evaluating Dynamic Econometric Models by encompassing the VAR", volume in honor of R.Bergstrom.

[55] Ingram, Beth, and Charles Whiteman(1994): "Supplanting the Minnesota Prior - Forecasting Macroeconomics Time Series using Real Business Cycle Model Priors," Journal of Monetary Economics, 34, 497-510.

[56] Ireland, Peter N. (2004): "A Method for Taking Models to the Data," Journal of Economic Dynamics and Control, 28, 1205-1226.

[57] Johansen, S. (1995). Likelihood Based Inference on Cointegration in the Vector Autoregressive Model. Oxford: Oxford University Press.

[58] Johansen, S. (2004) "How not to take a model to the data", mimeo

[59] Judd, Kenneth L. (1992): "Projection Methods for Solving Aggregate Growth Models,", Journal of Economic Theory, 58, 410-452.

[60] Judd, Kenneth L., and Sy-Ming Guu (1997): "Asymptotic methods for aggregate growth models," Journal of Economic Dynamics and Control, Elsevier, 21(6), 1025-1042

[61] Juselius K, and S. Johansen(1999) "Macroeconomic transmission mechanism. Empirical applications and econometric methods." paper available at http://www.econ.ku.dk/okokj/

[62] Juselius K., and M.Franchi(2007) "Taking a DSGE Model to the Data Meaningfully", Economics Discussion Papers, www.economicsejournal.org/economics/journalarticles/2007-4

[63] King, Robert G., Charles I. Plosser and Sergio T. Rebelo (1988): "Production, Growth and Business Cycles," Journal of Monetary Economics, 21, 195-232.

[64] Kydland Finn, and Edward Prescott (1982): " Time to Build and Aggregate Fluctuations," Econometrica, 50, 1345-70.

[65] Kydland, F., and Prescott, P. (1996). 'The Computational Experiment: an Econometric Tool'. Journal of Economic Perspectives, 10: 69-85.

[66] Koop, Gary (2003): "Bayesian Econometrics," John Wiley 83 Sons.

[67] Justiniano A. and G.E. Primiceri(2005) "The time-varying volatility of macroeconomic fluctuations", mimeo Princeton University

[68] Leeper, E. M. (1991), "Equilibria Under 'Active' and 'Passive' Monetary and Fiscal Policies," Journal of Monetary Economics 27, February, 129-47.

[69] Leeper, E. M., Sims, C. A., and Zha, T. (1996). 'What does monetary policy do?'. Available at http://eco072399b.princeton.edu/yftp/bpea/bpeaf.pdf 
[70] Lippi, M., and Reichlin, L. (1993). 'The dynamic effects of aggregate demand and supply disturbances: comment'. American Economic Review, 83, 3: 644-652.

[71] Liu T.-C.(1960) "Underidentification, Structural Estimation and Forecasting", Econometrica, 28,4, 855-865

[72] Lubik, Thomas, and Frank Schorfheide (2003): "Computing Sunspot Equilibria in Linear Rational Expectations Models," Journal of Economic Dynamics and Control, 28(2), 2003, 273-285.

[73] Lubik, Thomas, and Frank Schorfheide (2004):"Testing for Indeterminacy: An Application to U.S. Monetary Policy," American Economic Review, 94, $1,190-217$.

[74] Lucas, R. E. Jr. (1972). 'Expectations and the Neutrality of Money'. Journal of Economic Theory, 4, 103-124.

[75] Lucas, R. E. Jr. (1976). 'Econometric Policy Evaluation: A Critique'. In K. Brunner and A. Meltzer (eds.) The Phillips curve and labor markets. Amsterdam: North-Holland.

[76] Maddala (1988) Introduction to Econometrics, Mac Millan, New York, NY

[77] Mc Callum B.T.(1999) "Recent Developments in the Analysis of Monetary Policy Rules", Federal Reserve Bank of St.Louis Review, 3-11.

[78] McGrattan, Ellen R. (1999): "Application of Weigthed Residuals Methods to Dynamic Economic Models," in R. Marimom and A. Scott (eds) Computational Methods for the Study of Dynamic Economies. Oxford University Press.

[79] Pesaran M.H and Y.Shin (1998) "Generalized Impulse Response Analysis in Linear Multivariate Models" Economics Letters, 58, 17-29

[80] Pesaran M.H and Y.Shin (2002) "Long-run structural modelling", Econometric Reviews, 21, 49-87

[81] Rotemberg, Julio, and Micheal Woodford (1997): "An OptimizationBased Econometric framework for the Evaluation of Monetary Policy," NBER Macroeconomics annual, 12, 297-246.

[82] Rudebusch, G. D. (1998). 'Do Measures of Monetary Policy in a VAR Make Sense?'. International Economic Review, 39, 907-931.

[83] Ruge-Murcia, Francisco J. (2003): "Methods to estimate Dynamic Stochastic General Equilibrium Models," CIREQ, Cahier 17-2003. 
[84] Schmitt-Grohé, Stephanie, and Martin Uribe (2002): "Solving Dynamic General Equilibrium Models Using a Second-Order Approximation to the Policy Function," NBER Technical Working Paper 282.

[85] Schorfheide, Frank (2000): "Loss Function-Based evaluation of DSGE Models," Journal of Applied Econometrics, 15, S645-670.

[86] Sims, C. A. (1980). 'Macroeconomics and Reality'. Econometrica, 48, 1-48.

[87] Sims, C.A (1992): "Interpreting the Macroeconomic Time Series facts: The Effects of Monetary Policy," European Economic Review, XXXVI, 975-1000.

[88] Sims, C.A (2002): "Solving Linear rational expectations Models," Computational Economics, 20 (1-2), 1-20.

[89] Sims, C.A (2007) "Interview with Christopher Sims", Federal Reserve Bank of Minneapolis, http://www.minneapolisfed.org/pubs/region/0706/sims.cfm

[90] Sims, C.A and Tao Zha (1998): "Bayesian Methods for Dynamic Multivariate Models," International Economic Review, 39, 949-968.

[91] Sims, C. A. (1980b). 'Comparison of interwar and postwar business cycles: monetarism reconsidered'. American Economic Review, 250-257.

[92] Sims, C. A., Stock, J. H., and Watson, M. (1990). 'Inference in linear time-series models with some unit roots'. Econometrica, 58: 113-144.

[93] Sims, C. A., and Zha, T. (1996). 'Does Monetary Policy Generate Recessions?'. Mimeo. Available at ftp://ftp.econ.yale.edu/pub/sims/mpolicy

[94] Smets, Frank, and Raf Wouters (2003): "An Estimated Stochastic Dynamic General Equilibrium Model of the Euro Area," Journal of the European Economic Association, 1, 1123-75.

[95] Smith, Anthony (1993): "Estimating Nonlinear Time-Series Models Using Simulated Vector Autoregressions," Journal of Applied Econometrics, 8, S63-S84.

[96] Stock, James, and Mark Watson (2002): "Macroeconomic Forecasting Using Diffusion Indexes," Journal of Business Economics and Statistics, 20, 2, 147-162.

[97] Taylor J.B. (2005) "Thirty Five Years of Model Building for Monetary Policy Evaluation:Breakthroughs, Dark Ages, and a Renaissance", mimeo

[98] Tauchen, George (1986): "Finite State Markov-chain approximations to Univariate and Vector Autoregressions," Economics Letters 20, 177-181. 
[99] Theil, Henry, and Arthur S. Goldberg (1961): "On Pure and Mixed Estimation in Economics," International Economic Review, 2, 65-78.

[100] Uhlig, Harald (1999): "A Toolkit for Analyzing Nonlinear Dynamic Stochastic Models easily," in R. Marimom and A. Scott (eds) Computational Methods for the Study of Dynamic Economies. Oxford University Press.

[101] Uhlig, Harald (2001): "What are the effects of Monetary Policy? Evidence from an Agnostic Identification Procedure," Mimeo, Humboldt University. 